\title{
Developing a Financial Sustainability Model of the Performance Indicators Applied by Jordan Water Company (Miyahuna)
}

\author{
L. OWAIS ${ }^{1}$, J. T. KISS 2
}

${ }^{1}$ University of Debrecen, Faculty of Economics and Business Ihrig Károly Doctoral School, Ph.D. Student, Debrecen, Hungary, owais.lubna@eng.unideb.hu

${ }^{2}$ University of Debrecen, Faculty of Engineering, Department of Engineering Management and Enterprises, Associate Professor, Debrecen, Hungary, tkiss@eng.unideb.hu

\begin{abstract}
Jordan is now facing real challenges to satisfy the current population water needs due to the limited resources. Moreover, unfortunately, as a result of the increased demand for water in developing countries water resources become scarce, thus, the sustainable management of water resources is very important everywhere and especially in these areas. The Ministry of Water and Irrigation in Jordan is aiming to improve both its quality of service and financial sustainability, therefore, it started to apply the performance measurement system developed by the International Water Association (IWA) to monitor its performance towards achieving these goals. In this article, a model connecting a financial sustainability indicator (operating cost coverage ratio) with other performance indicators applied by the ministry is developed. To assess the performance indicators and to build the model secondary data are collected from the targeted company, the data are analysed using SPSS and Excel computer programs. Nonrevenue water (NRW), speed of repair of bursts, and training per employee are found to be the indicators that have a major impact on Miyahuna's financial sustainability, the NRW is found to have a negative relationship with the financial sustainability, whereas the other two indicators have a positive relationship. As a conclusion, reducing the NRW and increasing both the speed of repair and training per employee are recommended, by applying some methods that continuously diagnose problems in the water systems and defining clear and strict policies to control the water theft. Furthermore, using Active Leakage Control (ALC) methods, providing the needed equipment, tools and resources, and adopting new methods for training.
\end{abstract}

Keywords. Performance measurement systems, performance indicators, financial sustainability, operating cost coverage ratio.

\section{Introduction}

In order to improve a company's performance and measure a company's achievement toward its goals and success it has to monitor, measure, analyse and evaluate its performance through some measures. "A performance measurement system can be defined as the set of indicators used to quantify both the efficiency and effectiveness of actions" [1], Nappi and Henrique [2] explained that performance measurement system is a vital part of any company's managerial system. It is considered an important performance assessment approach as long as the performance indicators are chosen carefully to be relevant to the company's field of work and can be calculated, analysed, and evaluated. 
Water is considered one of the most important factors for the human body, for everyday life, and of course, it is very important to maintain a healthy ecosystem. Water has different standards for every use, for example, the definition of good water quality for drinking is: "the proportion of samples or supplies that comply with guideline values for drinking-water quality and minimum criteria for treatment and source protection" [3]. Unfortunately, as a result of the increase in the water demand in developing countries, water resources become scarce [4]. Therefore, the sustainable management of water resources is very important everywhere and especially in these areas. The Ministry of Water and Irrigation in Jordan is aiming to improve the quality of services and enhancing the financial sustainability of the Jordanian Water Sector, it is applying several performance indicators to measure the performance of water companies. Important to be mentioned that some indicators to measure both financial and environmental sustainability are also applied by the ministry according to the International Water Association (IWA) recommendations. In this article the performance indicators which are currently applied by Jordan Water Company (Miyahuna) are investigated, they are analysed and evaluated, then a model is built connecting the financial sustainability indicator and the indicators that have the most impact on it. Furthermore, to provide general recommendations and solutions to improve the financial performance of the company, after investigating the relationship between the indicators and financial sustainability.

\section{Water situation in Jordan}

The Hashemite Kingdom of Jordan is a small country located in one of the driest regions in the Middle East with very limited natural resources, and it is ranked as the world's second water poorest country. Jordan is located in an arid to semi-arid part of the region where water resources are limited and scarce. Clean water was already scarce, and currently, the limited resources unfortunately, must serve a very larger population. Jordan is currently hosting over two million refugees from Palestine, Iraq, and Syria, which makes it challenging to cover all these populations needs depending on the limited available resources. [5]

In response to the growing challenges in the water sector and in order to improve the provision of services to the Capital City of Amman, the Jordan Water Company (Miyahuna) was established in 2007 as a limited liability company under the Company Law of Jordan. It is headed by a CEO that is appointed by the Board of Directors. It is fully owned by the Water Authority of Jordan (WAJ) and has a staff of 1,500 active employees. It is currently responsible for supplying water and wastewater services for the capital Amman, Madaba, and Zarqa. [6]

\section{Performance measurement systems}

Performance measurement system enables the enterprises to plan, measure, and control their performance according to the enterprise pre-defined strategies [7], and the main goal of applying any measurement system is to get feedback that is in connection with the set goals, in which by these feedbacks both the chances of that goals are being achieved in efficient and effective way would significantly increase, and the decision-making process is supported [8]. The measurement results in true value if used as the basis for timely decisions. Each measurement system is unique, and the organisation's vision, mission, and goals are reflected in this system, in addition to measures tuned to financial, customer, internal organisation, and work process need. The generating of performance systems to deliver information assumes that it will eventually lead to improving the performance 
because it will be purposefully used by the leaders and managers of the organisations to managing the plans, programs, and allocate resources in the most effective ways [9].

\subsection{Performance measurement systems in the field of water utilities}

The water industry nowadays is facing some serious major challenges such as improving the quality of service (the continuous improvement of service is an essential target to be achieved), convoying with the population growth, and of course achieving sustainability of the new and the already existing services (which is a very difficult thing). Using a performance measurement system plays an important role, by always conducting a motivation for the water undertaking to increase effectiveness, efficiency, and improve the quality of service. It is believed that the right tool to help solving some of the major problems of the water sector is by assessing the water supply services performance [10]. The performance measurement systems provide not only values of ratios, but also the other corresponding elements, such as the context, factors, and the quality of the data that are also needed in order to make decisions.

The most important thing about the performance measurement system is that when applied, it takes into consideration all areas of interests, stakeholders, and factors that have the most effect in a certain environment. According to the International Water Association in the case of water undertakings, the system involves the entire company/organisation, the stakeholders, the users, the environment, and all the other parts that need to be observed for management purposes.

\subsection{Performance indicators (PIs) according to the International Water Association (IWA)}

IWA defined performance indicators as "measure of the efficiency and effectiveness of the delivery of the services by an undertaking that results from the combination of several variables. The information provided by a performance indicator is the result of a comparison (to a target value, previous values of the same indicator, or values of same indicators from other undertakings)." [11]

IWA identified 170 PIs in their performance measurement system that is based upon 232 different variables that need to be frequently observed. Performance indicators for water supply are arranged into six major groups that cover all aspects of the water system, and for all uses. These groups are water resources, personnel, physical, operational, quality of service, and economic and financial. Each one of these groups is also divided into subgroups, and in some special cases, these subgroups are also broken down into smaller units. The main assumption of the IWA PIs is that they have been chosen carefully in a way that they will be general as possible in order to be used in different situations. The IWA PIs are based on a holistic approach that does not take into consideration any special conditions and does not consider any problem that may arise while applying the system. Kanakoudis et al. [12] described this PIs system as being based on the typical super-market concept, and that it neglects practical problems that may arise during the application process as unreliable or even lacking data or local conditions. Alegre et al. [13] in their paper about highlights in IWA PIs system stated that the system is only general guidance, and to outline the importance and applicability of each indicator for the organisation is up to each undertaking. Moreover, they explained that according to the utility's needs and objectives any subset can easily be selected, and it is also free for users to divide the present indicators into subcategories or add their own indicators, if the degree of detail taken into account is considered insufficient. 


\subsection{Performance Indicators applied by Jordan Water Company (Miyahuna)}

The Ministry of Water and Irrigation is applying performance indicators to monitor and measure the performance of Jordanian water companies. Miyahuna is applying 26 different PIs divided into three levels, and the ten level 1 indicators are considered the most important ones, since they are used to measure the utility's performance towards achieving the MWI strategic goals of improved and sustainable water services, besides providing an overview of the stability of the utility to the stakeholders (e.g., the public, the decision-makers in MWI/WAJ, the board of directors and the top management of the company, etc.). While level 2 and 3 "assess the annual performance of Jordan Water Company by applying the agreed-upon performance indicators (PIs) adapted by the Program Monitoring Unit (PMU) in accordance with the Assignment Agreement signed between WAJ and Miyahuna" [14]. Table 1 below summarises the applied PIs by Miyahuna.

\begin{tabular}{|c|c|}
\hline \multicolumn{2}{|c|}{ Level 1} \\
\hline Water consumption per capita & $\begin{array}{l}\text { Operating cost coverage ratio (water and } \\
\text { sewerage) }\end{array}$ \\
\hline Microbiological water quality & Subscribers receiving continuous supply \\
\hline Water losses per water service connection & Non-billing (service) complaints \\
\hline Non-revenue water (NRW) by volume & Billing complaints \\
\hline Collection ratio & Total employees per 1000 subscribers \\
\hline \multicolumn{2}{|c|}{ Levels 2 and 3} \\
\hline Inefficiency of use of water resource & Network repair rate \\
\hline Water resource use per capita per day & Water service connection repair rate \\
\hline Water quality tests performed & 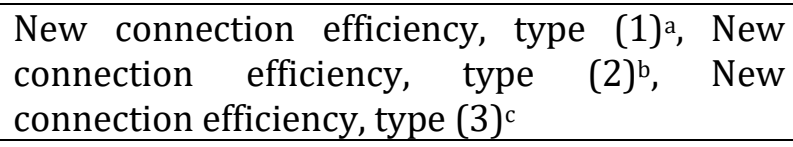 \\
\hline Quality of supplied water & Speed of repair of bursts \\
\hline Physical - chemical water quality compliance & Subscriber meter replacement \\
\hline Water quality complaints & Water losses per km of network \\
\hline Continuity of supply (Supply Index) & Average unit energy consumption \\
\hline $\begin{array}{l}\text { Employees (water) per } 1000 \text { water service } \\
\text { connection }\end{array}$ & Training per employee \\
\hline
\end{tabular}

Table 1. PIs applied by Miyahuna [14].

\section{Sustainability}

The sustainability topic is receiving considerable attention worldwide, and the effective management and use of natural resources are essential to guarantee satisfying both current and future generations' needs. Rehan et al. [15] mentioned that there is a current huge pressure on water utilities to provide both water supply and sewage services, and at the same time to be financially sustainable on the long term, Prinz and Anupam [4] identified that a water utility is considered financially sustainable when its 
revenues are equal or greater than its costs. To be financially sustainable is a very important issue especially in the countries which suffer from water scarcity, mainly due to the fact discussed by Banerjee et al. [16] that financially inefficient utilities result in overconsumption and waste of the scarce water resources, which eventually lead to affecting the economy negatively. It is discussed in the literature that many water utilities do not operate efficiently in terms of revenues, especially in developing countries [17]. Tsagarakis [18] discussed that what could be an important factor affecting the financial performance of the utilities is their size and the size of the population they serve. Miyahuna is aware of the importance of sustainable development especially due to the limited resources, therefore, the performance measurement system that is currently applying includes some indicators related to measuring economic and financial as well as environmental sustainability.

\section{Research methodology}

The main aim of this article is to develop a regression model of a financial sustainability indicator (operating cost coverage ratio) and link it with other performance indicators that effect it the most. To achieve this aim secondary data are collected, the quantitative secondary data used to build the model are collected from Miyahuna company, which are quarterly measures of all performance indicators applied by Miyahuna for the period between 2009 until the first half of 2018. The dependent variable of the model is the operating cost coverage ratio (OCCR) indicator, and to identify the model's independent variables a correlation analysis between OCCR and all performance indicators applied by Miyahuna is performed using SPSS software. The indicators that are found most correlated to the dependent variable are used as independent variables to build the model, and many trials are performed to achieve a final reliable regression model using Excel software. A brief evaluation of the independent variables' performance is performed, and some charts are provided based on the available time-series data. Finally, some general recommendations are provided to improve the performance of the independent variables, which will eventually improve the financial sustainability performance.

\section{Results}

\subsection{Performance indicators evaluation}

This part is about introducing and evaluating the performance of the dependent and independent variables that are included in the final model, as well as evaluating one performance indicator used by Miyahuna to measure environmental sustainability.

- Operating cost coverage ratio (OCCR) indicator

Operating Cost (water and sewerage) Coverage Ratio (Fic03), it falls in the financial category, it is the ratio between water and wastewater revenues and the total water and wastewater services operating costs for the same period, and it measures the financial sustainability of the utility [14]. Cost recovery is important in the field of water supply services as it ensures achieving adequate financing for the operations, maintenance, repairs and rehabilitation [19]. Operating cost coverage ratio has been used as a basic key indicator to evaluate the water utilities' financial performance [20]. Figure 1 shows that the operating costs were recovered all the years from 2009 until 2017 except in 2014. 


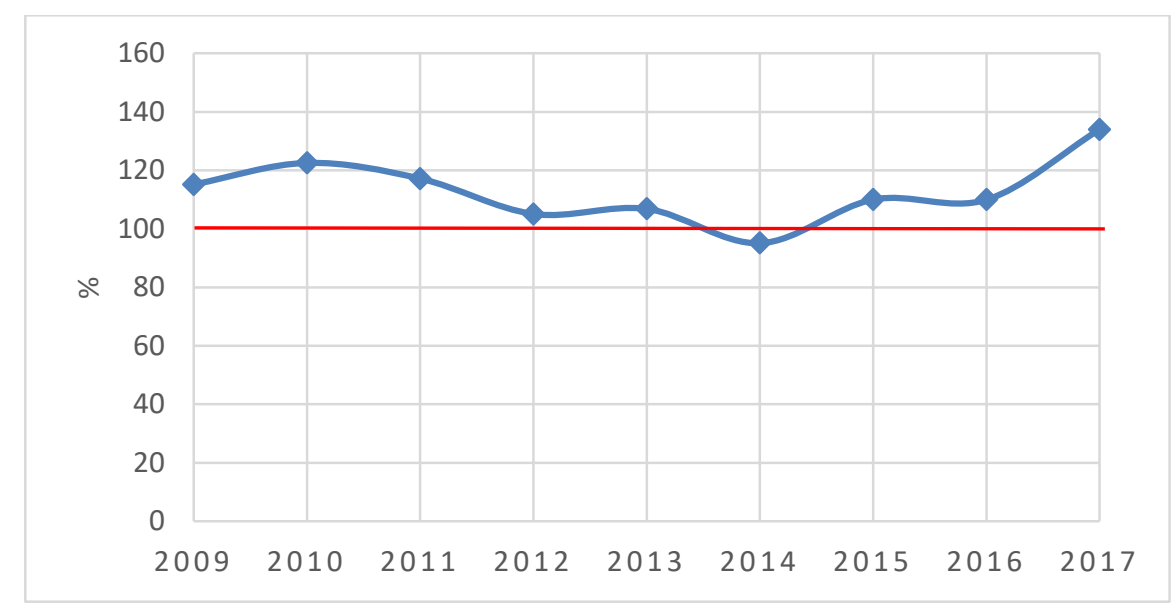

Figure 1. Operating cost coverage ratio [14].

- Speed of repair of bursts (\% of bursts)

Speed of repair of bursts (OPc08), it is an operational indicator, it measures the speed at which main leaks and bursts are repaired (speed of the maintenance response time). The long-term evaluation in Figure 2 shows that the speed of repair is exhibiting an increasing trend since 2013 to reach about $100 \%$ in 2017 , and this is a valued achievement.

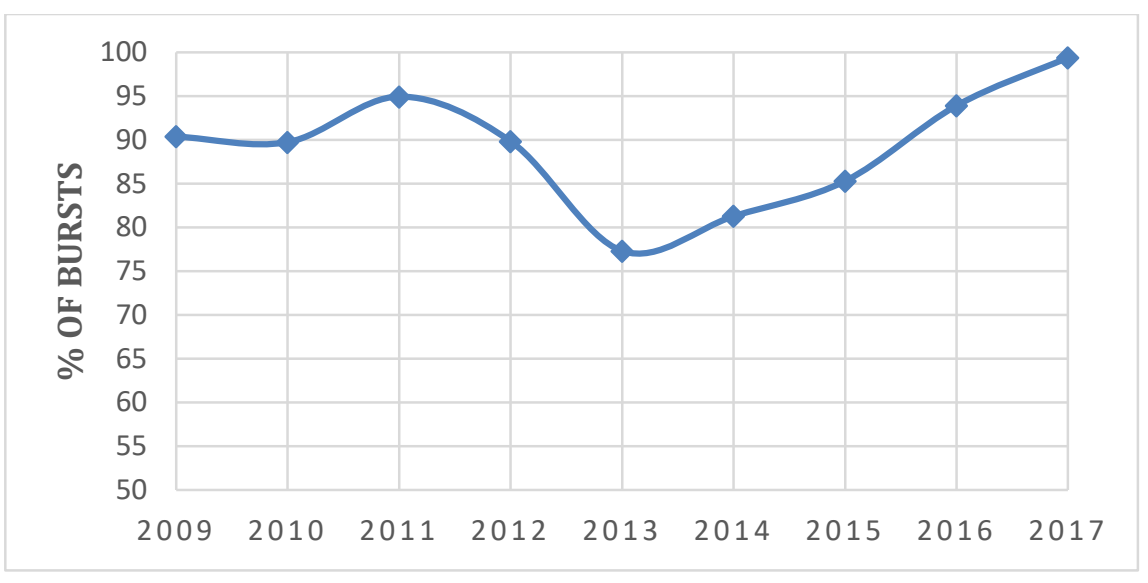

Figure 2. Speed of repair [14].

- Inefficiency of use of water resources

Inefficiency of use of water resources (WR01), it's an indicator in the water resources category. It measures the proportion of "System Input Volume" lost through leakage and other forms of real losses [14], and it is a measure of the environmental sustainability [10] [21]. Figure 3 below shows that until 2011 the inefficiency of use of water resources was decreasing with time, then after that, it started to increase at a high rate. This high rate increase after 2011 may indicate that there is a deterioration in the distribution network, which means that the need for revising maintenance practices and procedures is necessary. 


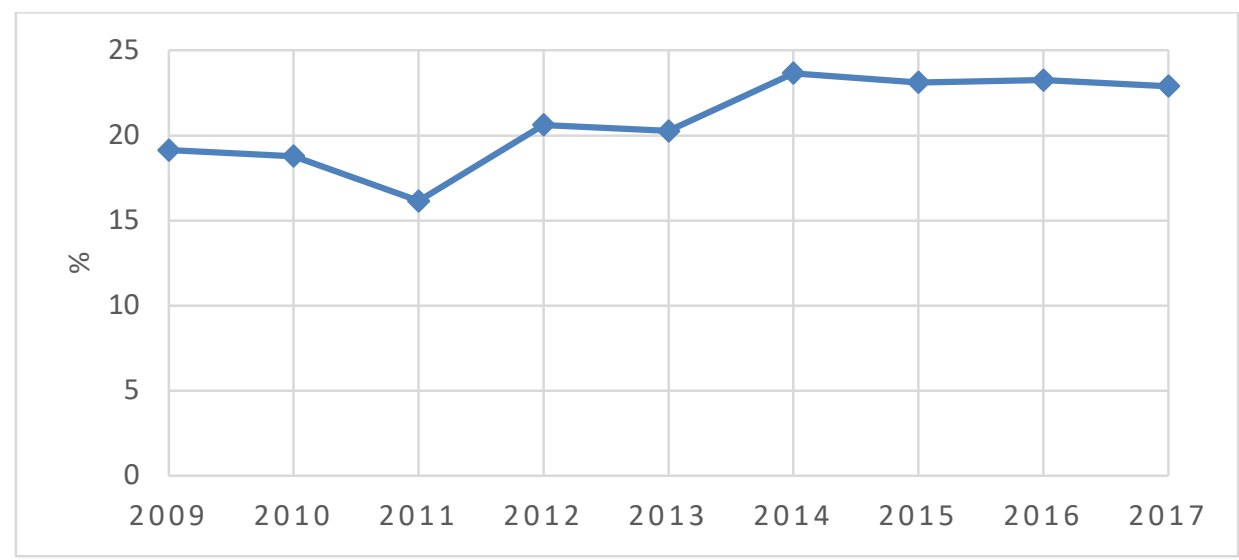

Figure 3. Inefficiency of use of water resources [14].

- Non-revenue water (NRW) by volume (\% of system input)

Non-Revenue Water by Volume (Fi36), it follows to the both financial and water loss categories, it is the difference between the volumes of system input and billed authorised consumption due to real and apparent losses as a percentage of system input by volume. It also indicates the technical conditions of the network including the meters [11]. As shown in Figure 4, the NRW shows a decreasing trend with time until 2011, after that it exhibited almost a constant rise ever since.

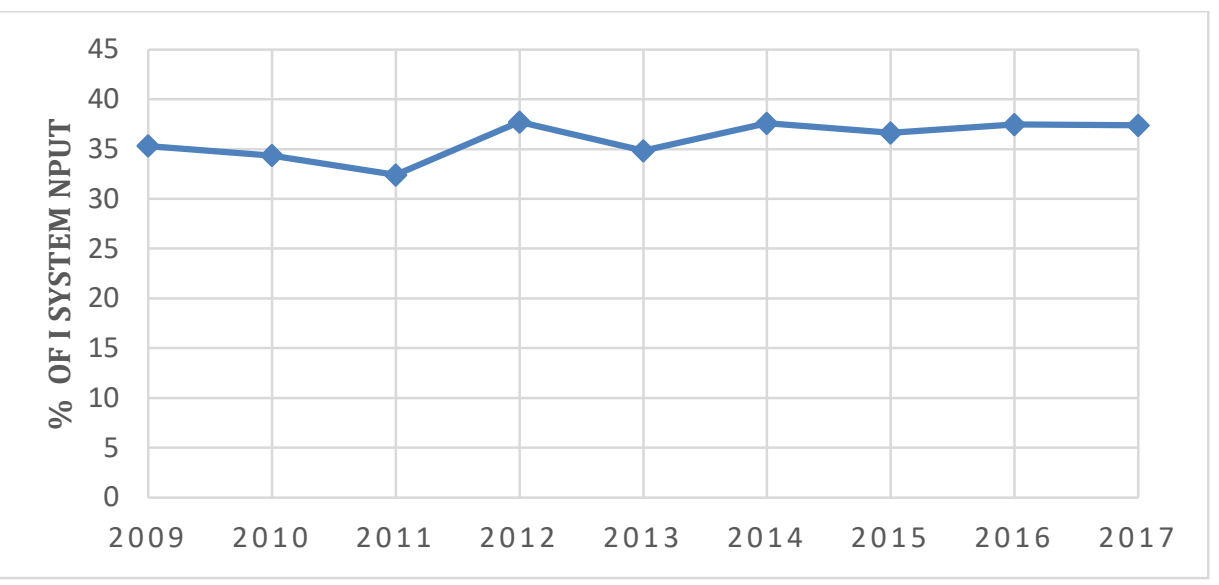

Figure 4. NRW by volume [14].

- $\quad$ Training per employee (d/employee /q)

Training per employee (Pe16), it is a personnel indicator that measures the provided training from the company to the employees. And according to Miyahuna's data [14], the training has significantly increased in 2017 compared to 2016 by (31\%), and this results in a positive impact on the company's productivity. Figure 5 below shows the significant increase in training per employee from 2015, which indicates Miyahuna's awareness of the importance of employees' training in improving the performance of the company. 


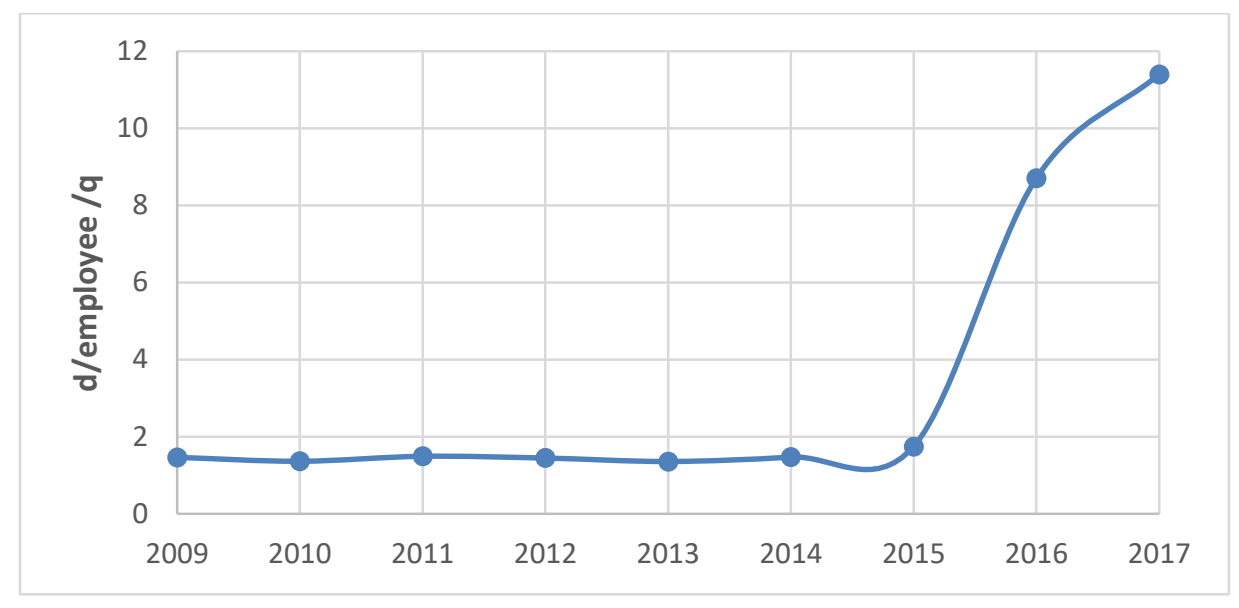

Figure 5. Training per employee [14].

\subsection{Correlation and Regression Analysis of the Operating Cost Coverage Ratio}

Correlation analysis is used to check the impact of each performance indicator on the operating cost coverage ratio (OCCR), this analysis is performed using SPSS software. The correlation analysis between the 26 indicators and the operating cost coverage ratio shows that there is a significant correlation between the OCCR and the following indicators: Water loss per water service connection (IND 1), NRW by volume (IND 2), non-billing complaints (IND 3), inefficiency of use of water resources (IND 4), water resource use per capita/ system input per day (IND 5), speed of repair of bursts (IND 6), subscribers meter replacement (IND 7), water losses per km of network (IND 8), average unit energy consumption (IND 9), and training per employee (IND 10). These indicators are used to develop the final regression model of the operating cost coverage ratio. Table 2 below shows the Pearson correlation coefficients (r) of the indicators that have a high significant correlation with the operating cost coverage ratio.

\begin{tabular}{lllllllllllc}
\hline & OCCR & IND 1 & IND 2 & IND 3 & IND 4 & IND 5 & IND 6 & IND 7 & IND 8 & IND 9 & IND \\
& & & & & & & & & & \\
\hline OCCR & 1 & & & & & & & & & & \\
IND 1 & $-.414^{* *}$ & 1 & & & & & & & & & \\
IND 2 & $-.452^{* *}$ & $.775^{* *}$ & 1 & & & & & & & & \\
IND 3 & $-.387^{*}$ & .129 & .235 & 1 & & & & & & & \\
IND 4 & $-.406^{*}$ & $.921^{* *}$ & $.928^{* *}$ & .065 & 1 & & & & & & \\
IND 5 & $-.365^{*}$ & $.814^{* *}$ & $.446^{* *}$ & $.388^{*}$ & $.574^{* *}$ & 1 & & & & & \\
IND 6 & $.427^{* *}$ & -.086 & .0154 & .006 & .053 & -.176 & 1 & & & \\
IND 7 & $.395^{*}$ & .006 & .055 & -.193 & -.001 & .040 & .271 & 1 & & & \\
IND 8 & $-.367^{*}$ & $.994^{* *}$ & $.765^{* *}$ & .103 & $.914^{* *}$ & $.815^{* *}$ & -.031 & .030 & 1 & & \\
IND 9 & $.414^{* *}$ & -.059 & .111 & .079 & -.010 & -.059 & $.680^{* *}$ & $.521^{* *}$ & .009 & 1 & \\
IND 10 & $.374^{*}$ & $.378^{*}$ & .268 & -.183 & $.341^{*}$ & .288 & $.523^{* *}$ & $.405^{*}$ & $.452^{* *}$ & $.756^{* *}$ & 1 \\
\hline \multicolumn{7}{c}{ Table 2. Correlation coefficients between operating cost coverage ratio and performance indicators. }
\end{tabular}

**. Correlation is significant at the 0.01 level (2-tailed).

*. Correlation is significant at the 0.05 level (2-tailed).

In order to achieve the main aim a regression analysis is performed, where the dependent variable is the operating cost coverage ratio, and the independent variables are the indicators found from the correlation analysis. To develop a final reliable model many trials are performed, and the most reliable 
regression model of the financial sustainability (operating cost coverage ratio) is assumed to be a multiple exponential model with three independent variables represented by the following general equation:

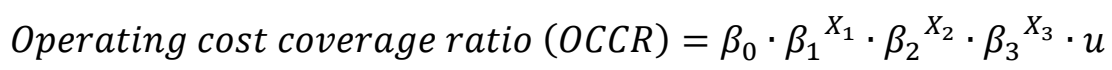

The achieved model has an acceptable value of adjusted $\mathrm{R}$ squared $=0.51$ and a very good value of 0.057 standard error, table 3 below summarises the results of the OCCR regression analysis. The model shows significant results, since the $95 \%$ confidence interval column shows that for all indicators at a given significant level (5\%), the confidence interval (95\%) may not include the value of zero for the all three indicators. This means that $95 \%$ is the probability that the given slope coefficients of these independent variables may not be zero, which indicates that all of the three indicators are significant in our model.

\begin{tabular}{llllll}
\hline & $\begin{array}{l}\text { Regression } \\
\text { coefficient } \\
(\beta)\end{array}$ & SE & t Stat & $P$-value & $\begin{array}{l}\text { 95\% Confidence } \\
\text { Interval }\end{array}$ \\
\hline Intercept & 2.0689 & 0.1301 & 15.9009 & $2.5949 \mathrm{E}-17$ & $(1.8045)-(2.3334)$ \\
NRW & -0.0091 & 0.0018 & -5.1447 & $1.1150 \mathrm{E}-05$ & $(-0.0126)-(-0.0055)$ \\
Speed of repair & 0.0032 & 0.0013 & 2.3704 & 0.0236 & $(0.0005)-(0.0059)$ \\
$\begin{array}{l}\text { Training per } \\
\text { employee }\end{array}$ & 0.0274 & 0.0106 & 2.5853 & 0.0142 & $(0.0059)-(0.0489)$ \\
\hline
\end{tabular}

Table 3. Summary of OCCR regression analysis.

From the results shown above, the OCCR is found to have the following equation:

$$
Y=117.206 * 0.97937^{X_{1}} * 1.00734^{X_{2}} * 1.06505^{X_{3}}
$$

Where:

Y: Operating cost coverage ratio (\%)

$\mathrm{X}_{1}$ : Non-revenue water by volume (\% of system input)

$\mathrm{X}_{2}$ : Speed of repair of bursts (\% of bursts)

$\mathrm{X}_{3}$ : Training per employee (d/employee/q)

The model shows the following relationships between the dependent and independent variables:

$\mathrm{Y}$ and $\mathrm{X}_{1}$ have a negative relationship, whenever $\mathrm{X}_{1}$ increases $\mathrm{Y}$ decreases.

$\mathrm{Y}$ and $\mathrm{X}_{2}$ have a positive relationship, whenever $\mathrm{X}_{2}$ increases $\mathrm{Y}$ increases.

$\mathrm{Y}$ and $\mathrm{X}_{3}$ have a positive relationship as well, whenever $\mathrm{X}_{3}$ increases $\mathrm{Y}$ increases.

To explain the rate at which each indicator affects the operating cost coverage ratio the elasticity index

$(\varepsilon)$ is used, and its final formula that describes the relation for exponential regressions is:

$$
\varepsilon_{x i, y}=X_{i f} \ln \beta_{i}
$$

Where:

$\varepsilon_{x i, y}$ : the elasticity between $X_{i}$ and $\mathrm{Y}$ 
$X_{i f}$ : the latest measured value of the independent variable $\left(X_{i}\right)$

$\beta_{i}$ : the slope coefficient of the independent variable $\left(X_{i}\right)$

This formula describes the percent changes of $\mathrm{Y}$ if $\mathrm{X}$ changes by one percent from its latest measured value.

* Indicator 1:

$$
\begin{aligned}
\varepsilon_{x i, y} & =41.3604 * \ln (0.97937) \\
= & -0.86 \%
\end{aligned}
$$

This means that every $1 \%$ increase in the latest measured value of X (41.3604), Y will decrease by $0.86 \%$.

* Indicator 2:

Every $1 \%$ increase in the latest measured value of $\mathrm{X}$ (98.6316), $\mathrm{Y}$ will increase by $0.72 \%$.

* Indicator 3:

Every $1 \%$ increase in the latest measured value of $X$ (2.09501), $Y$ will increase by $0.13 \%$.

According to these findings and to achieve a significant improvement Miyahuna must work to enhance the performance of these indicators. Some general solutions and preventative procedures may be recommended:

To decrease the amount of the non-revenue water, Miyahuna must work on controlling both real and apparent losses. Common solutions are the rehabilitation of the water networks, increasing the speed of response to any failure in the connections, as well as implementing one of the new methods or techniques that are being used to continuously monitor and diagnose problems in the water infrastructure and distribution systems such as Smart Water Grid, Automated Meter Reading (AMR), Advanced Metering Infrastructure (AMI), Supervisory Control And Data Acquisition (SCADA), and the Active Leakage Control (ALC) methods, another important and widely used solution to control the real losses is the pressure management technique. Adopting such methods rather than just relying on leaks reporting by the public is a very important solution. The apparent losses are mainly caused by unauthorised consumption, customer meter inaccuracies, and systematic data handling errors. They can be controlled by setting up new digital meters (electromagnetic and ultra-sonic meters) that provides more accurate readings, and for the unauthorised consumption clearly defined policies and regulations for such provisions must be provided by the water companies to detect common thefts in the water supply, metering and billing processes. It is also very important to work on raising the local community awareness.

Speed of repair can be improved by improving the response to leaks, which depends on equipment and trained people (on both the detection and the repair processes), resources, etc.

Training of employees is a key success factor in any business, and some training methods may be recommended to be used for example, Computer Based Trainings (CBT), e-learning trainings, video trainings, coaching and mentoring, workshops, On-The-Job trainings, and lectures.

\section{Conclusion}

There are many ways to judge a company's performance, but the most important is the right selection of the measures for that. The frequent act of monitoring, measuring, analysing and evaluating processes 
has a great impact on the performance, current and future success of the company, as well as its stability. Our today's actions have a major impact on future generations, and mainly they affect their ability to satisfy their basic needs. Therefore, sustainable development is very important everywhere and especially in developing countries where the resources are limited and scarce. It is the responsibility of both the public and private sectors to achieve sustainable development by applying all needed procedures and actions to achieve this sustainable development. Identifying some indicators to improve both utilities and environmental sustainability is highly important, hence these indicators will help the utilities to conclude the procedures they must invest the most effort at to achieve better financial and environmental sustainability.

Miyahuna's financial sustainability model shows that the non-revenue water by volume, speed of repair of bursts, and training per employee are the indicators that have a major impact on its financial sustainability performance. Both of speed of repair and training per employee have a positive relationship with the operating cost coverage ratio, while the NRW has a negative relationship. Improving the performance of these indicators will absolutely assure improving the financial sustainability performance of Miyahuna, real losses can be controlled by the rehabilitation of the networks, improving the response time, and applying pressure management techniques. Implementing new methods to continuously monitor and diagnose problems in the water infrastructure and distribution systems is also important to reduce the real losses. Defining strict policies and regulations to limit and control the water thefts and raising the local community awareness are recommended procedures to control the apparent losses. Finally, training of the employees, enhancing the employee's capacity using new training methods, and providing the required equipment, tools and resources are the most important factors to improve the maintenance response time.

\section{References}

[1] Neely, A., Gregory, M. and Platts, K., 1995. Performance measurement system design: a literature review and research agenda. International journal of operations \& production management, 15(4), pp.80-117.

DOI: $\underline{10.1108 / 01443579510083622}$

[2] Nappi, V. and Rozenfeld, H., 2015. The incorporation of sustainability indicators into a performance measurement system. Procedia CIRP, 26, pp.7-12. https://doi.org/10.1016/j.procir.2014.07.114

[3] World Health Organization (WHO), 1996. Guidelines for drinking-water quality, 2nd edn, vol 2 Health criteria and other supporting information. WHO, Geneva.

[4] Prinz, D. and Singh, A.K., 2000. Water resources in arid regions and their sustainable management. Annals of Arid Zone, 39(3), pp.251-272. DOI: 10.5445/IR/24252000

[5] Jordan Water Sector facts and figures, 2017. Online http://www.waj.gov.jo/sites/en-us/default.aspx. (Accessed 10 May 2019)

[6] Miyahuna official website. Online http://miyahuna.com.jo/en. (Accessed 17 Dec 2018) 
[7] Johnson, C.C., Beiman, I. and Thompson, J., 2007. Balanced Scorecard: for State-owned Enterprises: Driving Performance and Corporate Governance. Asian Development Bank. http://hdl.handle.net/11540/228

[8] Alegre, H., Cabrera Rochera, E., Hein, A. and Brattebø, H., 2014. Framework for Sustainability Assessment of UWCS and development of a self-assessment tool. http://hdl.handle.net/10251/35738

[9] Moynihan, D.P., Fernandez, S., Kim, S., LeRoux, K.M., Piotrowski, S.J., Wright, B.E. and Yang, K., 2011. Performance regimes amidst governance complexity. Journal of public administration research and theory, 21(suppl_1), pp.i141-i155. https://doi.org/10.1093/iopart/muq059

[10] Alegre, H., Baptista, J.M., Cabrera Jr, E., Cubillo, F., Duarte, P., Hirner, W., Merkel, W. and Parena, R., 2006. Performance Indicators for Water Supply Services. IWA Publishing. ISBN: 1843390515

[11] Alegre, H., Baptista, J.M., Cabrera Jr, E., Cubillo, F., Duarte, P., Hirner, W., Merkel, W. and Parena, R., 2016. Performance indicators for water supply services. IWA publishing. ISBN: 978178046336

[12] Kanakoudis, V., Tsitsifli, S., Samaras, P., Zouboulis, A. and Demetriou, G., 2011. Developing appropriate performance indicators for urban water distribution systems evaluation at Mediterranean countries. Water Utility Journal, 1, pp.31-40.

[13] Alegre, H., Hirner, W., Baptista, J.M. and Parena, R., 2002. Highlights of the IWA system of performance indicators for water supply services. In Beitrag zum Workshop „Views and Experience Gained Through Implementing IWA Performance Indicators Project ", im Rahmen des 3rd World Water Congress in Melbourne (Vol. 7, No. 12.04, p. 2002).

[14] Jordan Water Company Miyahuna annual monitoring report, 2018.

[15] Rehan, R., Knight, M.A., Haas, C.T. and Unger, A.J., 2011. Application of system dynamics for developing financially self-sustaining management policies for water and wastewater systems. Water research, 45(16), pp.4737-4750. https://doi.org/10.1016/j.watres.2011.06.001

[16] Banerjee, S., Skilling, H., Foster, V., Briceño-Garmendia, C., Morella, E. and Chfadi, T., 2008. Africa infrastructure country diagnostic: Urban water supply in Sub-Saharan Africa. Report by the World Bank and the Water and Sanitation Programme.

[17] Mutikanga, H.E., Sharma, S.K. and Vairavamoorthy, K., 2011. Multi-criteria decision analysis: a strategic planning tool for water loss management. Water resources management, 25(14), p.3947. https://doi.org/10.1007/s11269-011-9896-9

[18] Tsagarakis, K.P., 2013. Does size matter? Operating cost coverage for water utilities. Water resources management, 27(5), pp.1551-1562. https://doi.org/10.1007/s11269-012-0256$\underline{1}$ 
[19] Agyapong, D., 2017. Financial sustainability and cost recovery in small towns water systems in Eastern region of Ghana. pp.383-404. DOI: 10.30958/ajbe.3.4.2

[20] Bucknall J, Kremer A, Allan T, Berkoff J, Abu-Ata N, Jarosewich-Holder M, Deichmann U, Susmita Dasgupta, Bouhamidi R, Ipe V., 2007. Making the Most of Scarcity: Accountability for Better Water Management Results in the Middle East and North Africa. Washington DC. ISBN: 9780821369258

[21] Duarte, A.A., Rodrigues, G.M.D.C. and Ramos, R.A., 2009. A global service quality index to evaluate the performance and sustainability in water supply utilities. pp.759-769. ISSN: 17905079 